\title{
Sevoflurane-induced hyperglycemia is attenuated by salsalate in obese insulin-resistant mice
}

\section{L'hyperglycémie induite par le sévoflurane est atténuée par le salsalate chez les souris obèses insulino-résistantes}

\author{
Eric M. Desjardins, MSc • Brennan K. Smith, PhD • Gregory R. Steinberg, PhD • \\ Russell E. Brown, MD, PhD (D)
}

Received: 22 June 2020/Revised: 2 December 2020/Accepted: 2 December 2020/Published online: 12 February 2021

(C) Canadian Anesthesiologists' Society 2021

\begin{abstract}
Purpose Perioperative hyperglycemia is common and is associated with significant morbidity. Although patient characteristics and surgery influence perioperative glucose metabolism, anesthetics have a significant impact. We hypothesized that mice that were obese and insulinresistant would experience greater hyperglycemia in response to sevoflurane anesthesia compared with lean controls. We further hypothesized that sevoflurane-induced
\end{abstract}

Supplementary Information The online version contains supplementary material available at https://doi.org/10.1007/s12630021-01935-1.

E. M. Desjardins, MSc - B. K. Smith, PhD

Centre for Metabolism, Obesity, and Diabetes Research,

McMaster University, Hamilton, ON, Canada

Division of Endocrinology and Metabolism, Department of Medicine, McMaster University, Hamilton, ON, Canada

G. R. Steinberg, $\mathrm{PhD}$

Centre for Metabolism, Obesity, and Diabetes Research, McMaster University, Hamilton, ON, Canada

Division of Endocrinology and Metabolism, Department of Medicine, McMaster University, Hamilton, ON, Canada

Department of Biochemistry and Biomedical Sciences,

McMaster University, Hamilton, ON, Canada

R. E. Brown, MD, PhD ( $\square)$

Centre for Metabolism, Obesity, and Diabetes Research, McMaster University, Hamilton, ON, Canada

e-mail: brownrus@hhsc.ca

Department of Anesthesia, McMaster University, McMaster University Medical Centre, 1200 Main St W, Room 2V9,

Hamilton, ON L8N 3Z5, Canada hyperglycemia would be attenuated by salsalate pretreatment.

Methods Lean and obese male C57BL/6J mice were anesthetized with sevoflurane for $60 \mathrm{~min}$ with or without pre-treatment of $62.5 \mathrm{mg} \cdot \mathrm{kg}^{-1}$ salsalate. Blood glucose, plasma insulin, and glucose uptake into different tissues were measured.

Results Under sevoflurane anesthesia, obese mice had higher blood glucose compared to lean mice. Increases in blood glucose were attenuated with acute salsalate pretreatment at 60 min under anesthesia in obese mice (mean \pm standard error of the mean [SEM], delta blood glucose; vehicle $5.79 \pm 1.09$ vs salsalate $1.91 \pm 1.32 \mathrm{mM} ; P=$ $0.04)$ but did not reach statistical significance in lean mice (delta blood glucose, vehicle $4.39 \pm 0.55$ vs salsalate 2.79 $\pm 0.71 \mathrm{mM} ; P=0.10)$. This effect was independent of changes in insulin but associated with an approx. 1.7-fold increase in glucose uptake into brown adipose tissue (vehicle $45.28 \pm 4.57 \mathrm{vs}$ salsalate $76.89 \pm 12.23 \mu \mathrm{mol} \cdot \mathrm{g}^{-1}$ tissue $\cdot \mathrm{hr}^{-1} ; \mathrm{P}<0.001$ ).

Conclusion These data show that salsalate can reduce sevoflurane-induced hyperglycemia in mice. This indicates that salsalate may represent a new class of therapeutics that, in addition to its anti-inflammatory and analgesic properties, may be useful to reduce perioperative hyperglycemia.

\section{Résumé}

Objectif L'hyperglycémie périopératoire est fréquente et est associée à une morbidité significative. Bien que les caractéristiques propres au patient et à la chirurgie influencent le métabolisme périopératoire du glucose, les anesthésiques ont un impact significatif. Nous avons émis l'hypothèse que l'hyperglycémie en réponse à une anesthésie à base de sévoflurane serait plus prononcée 
chez des souris obèses et insulino-résistantes que chez des souris témoins maigres. Nous avons en outre émis l'hypothèse que l'hyperglycémie induite par le sévoflurane serait atténuée par un prétraitement au salsalate.

Méthode Des souris mâles C57BL/6J maigres et obèses ont été anesthésiées avec du sévoflurane pendant $60 \mathrm{~min}$ avec ou sans prétraitement de $62,5 \mathrm{mg} \cdot \mathrm{kg}^{-1}$ de salsalate. La glycémie, l'insuline plasmatique et l'absorption glycémique ont été mesurées dans différents tissus.

Résultats Sous une anesthésie au sévoflurane, les souris obèses ont affiché une glycémie plus élevée que les souris maigres. Des augmentations de glucose sanguin ont été atténuées lors d'un prétraitement aigu à base de salsalate à 60 min sous anesthésie chez les souris obèses (moyenne \pm erreur-type sur la moyenne [ETM], delta glycémique; véhicule 5,79 $\pm 1,09$ vs salsalate $1,91 \pm 1,32 \mathrm{mM}, P=$ 0,04), mais elles n'étaient pas statistiquement significative chez les souris maigres (delta glycémique, véhicule 4,39 \pm $0,55$ vs salsalate 2,79 $\pm 0,71 \mathrm{mM} ; P=0,10)$. Cet effet était indépendant des changements de l'insuline mais associé à une augmentation d'environ 1,7 fois de l'absorption glycémique dans les tissus adipeux bruns (véhicule 45,28 $\pm 4,57$ vs salsalate $76,89 \pm 12,23 \mu \mathrm{mol} \cdot \mathrm{g}^{-1} \mathrm{tissu} \cdot \mathrm{h}^{-1} ; \mathrm{P}<$ 0,001).

Conclusion Ces données montrent que le salsalate peut réduire l'hyperglycémie induite par le sévoflurane chez la souris. Ceci indique que le salsalate pourrait constituer une nouvelle classe d'agents thérapeutiques qui, en plus de leurs propriétés anti-inflammatoires et analgésiques, pourraient être utiles pour réduire l'hyperglycémie périopératoire.

Keywords sevoflurane hyperglycemia diabetes · salsalate

Perioperative hyperglycemia (blood glucose $>11$ $\mathrm{mmol} \cdot \mathrm{L}^{-1}$ ) has been associated with a number of clinical complications including surgical site infections, sepsis, impaired wound healing, endothelial dysfunction, thrombus formation, myocardial ischemia, stroke, neurocognitive dysfunction, prolonged length of stay, and even death. ${ }^{1-7}$ Although its true incidence remains elusive because of variable definitions and testing, perioperative hyperglycemia is very common $(15-66 \%) .{ }^{8}$ Despite the apparent importance of perioperative hyperglycemia, its significance and consequences may be largely underappreciated clinically. ${ }^{9}$ Importantly, patient characteristics implicated in the development of hyperglycemia include increased body mass index, which raises important questions about the impact of obesity given its high incidence worldwide. ${ }^{4,8}$

The impact of volatile anesthetics on glucose and insulin metabolism have been described for more than a century. $^{10,11}$ Numerous studies have shown that anesthetics can cause hyperglycemia in animal models and clinical situations, even without surgical stress. ${ }^{12-16}$ Nevertheless, unlike adults, neonatal mice anesthetized with sevoflurane appear to develop hypoglycemia. ${ }^{16}$ Previous studies have attempted to improve glucose control perioperatively to reduce surgical complications; however, the most promising approach to date involved an insulin-based regime. ${ }^{7}$ Although insulin-based regimes improved glycemic control in surgical patients, the major concern that remains is the potential harm associated with severe hypoglycemic events as seen in critical care patients. $^{7,17}$ Therefore, there is an important need for new, safe, and effective therapies that lower blood glucose perioperatively without causing hypoglycemia.

Salsalate, a dimer of salicylate, is an anti-inflammatory that has been approved for treating rheumatoid arthritis for over 50 years. More recently, salsalate has been shown to lower blood glucose in people with type 2 diabetes without causing significant hypoglycemic events. ${ }^{18-21}$ Importantly, in contrast to acetylsalicylic acid (ASA), salsalate does not inhibit prostaglandin synthesis as there is no acetyl-group to inhibit cyclooxygenases, and will therefore not inhibit blood clotting or increase the risk for major bleeding events. $^{22}$ Previous investigations have shown that chronic oral salsalate administration leads to significant improvements in dysglycemic mice, and that clinically significant levels of salsalate can acutely be achieved after being injected. ${ }^{23,24}$ Currently, it is unknown whether salsalate can attenuate increases in blood glucose induced by anesthesia or surgery.

In the current study, we used a diet-induced obesity (DIO) mouse model that involves feeding C57BL/6 mice a high-fat diet (HFD) for several weeks, leading to significant weight gain, glucose intolerance, and insulin resistance. Unlike other genetic-based animal models of obesity, DIO recapitulates many of the features seen in humans with metabolic syndrome. ${ }^{25}$ We hypothesized that sevoflurane-induced hyperglycemia would be more pronounced in obese insulin-resistant mice, and that salsalate given acutely would attenuate this response.

\section{Methods}

Animals and diet

All experiments were approved by the McMaster University Animal Ethics Committee and conducted 
under the Canadian guidelines for animal research. Male C57BL/6J mice were purchased from the Jackson Laboratory, maintained on a 12-hr light dark cycle, and housed at $22-23^{\circ} \mathrm{C}$ with bedding and enrichment. For chow-fed vs DIO mouse experiments (see timeline in Fig. 1), 14 week-old mice were purchased from the Jackson Laboratory (\#000664 or \#380050; Jackson Laboratory, Bar Harbor, ME, USA) and given two weeks to acclimate before measuring the body weight, adiposity (as determined by time-domain nuclear magnetic resonance whole-body composition; minispec LF90II, Bruker), and glucose tolerance (as determined by intraperitoneal glucose tolerance test [ipGTT], which is described below). Mice were then assigned to groups based on these three factors. More specifically, mice on respective diets were ranked by ipGTT area under the curve before randomly being allocated to either vehicle or salsalate pre-treatment. Group means were then compared to determine any differences in body weight, adiposity, or ipGTT. There were no adverse events to report prior to the sacrificing of these research animals. The chow-fed mice used in this study were reused for pilot experiments to follow the 3Rs in the use of animals in research. On the day of the anesthesia challenge, mice were fasted at 07:00 and the challenge began at 13:00 to stage similar basal blood glucose levels.

For chronic salsalate supplementation (see timeline in eFigure [Electronic Supplementary Material]), mice were purchased from the Jackson Laboratory (\#000664) at six weeks of age. The timeline of the study was similar to as previously described. ${ }^{24}$ At eight weeks of age, mice were switched from a normal chow diet to a $60 \%$ kcal HFD (D12492 Research Diets). After five weeks of HFD, an ipGTT was performed to confirm glucose intolerance and groups were assigned by matching body weight, glucose tolerance, and adiposity as described above. Mice weighing less than $32 \mathrm{~g}$ at the five-week mark were excluded from the study. Once groups were assigned, mice were fed either HFD or HFD supplemented with $2.5 \mathrm{~g} \cdot \mathrm{kg}^{-1}$ salsalate (Cayman Chemicals, Ann Arbor, MI, USA) for five weeks before further metabolic testing (see timeline).

\section{Metabolic measurements}

\section{Intraperitoneal glucose tolerance test}

Following a six-hour fast from 07:00 to 13:00, ipGTT was performed at the indicated weeks in both groups of mice as previously described. ${ }^{24}$ Briefly, basal blood and glucose samples were obtained by nicking the tail vein prior to an intraperitoneal injection of $0.8 \mathrm{~g} \cdot \mathrm{kg}^{-1}$ dextrose. Blood glucose values were measured at $0,20,40,60,90$, and 120 min using Accu-Chek blood glucose monitors (Roche Diabetes Care, Inc., Laval, QC, Canada).

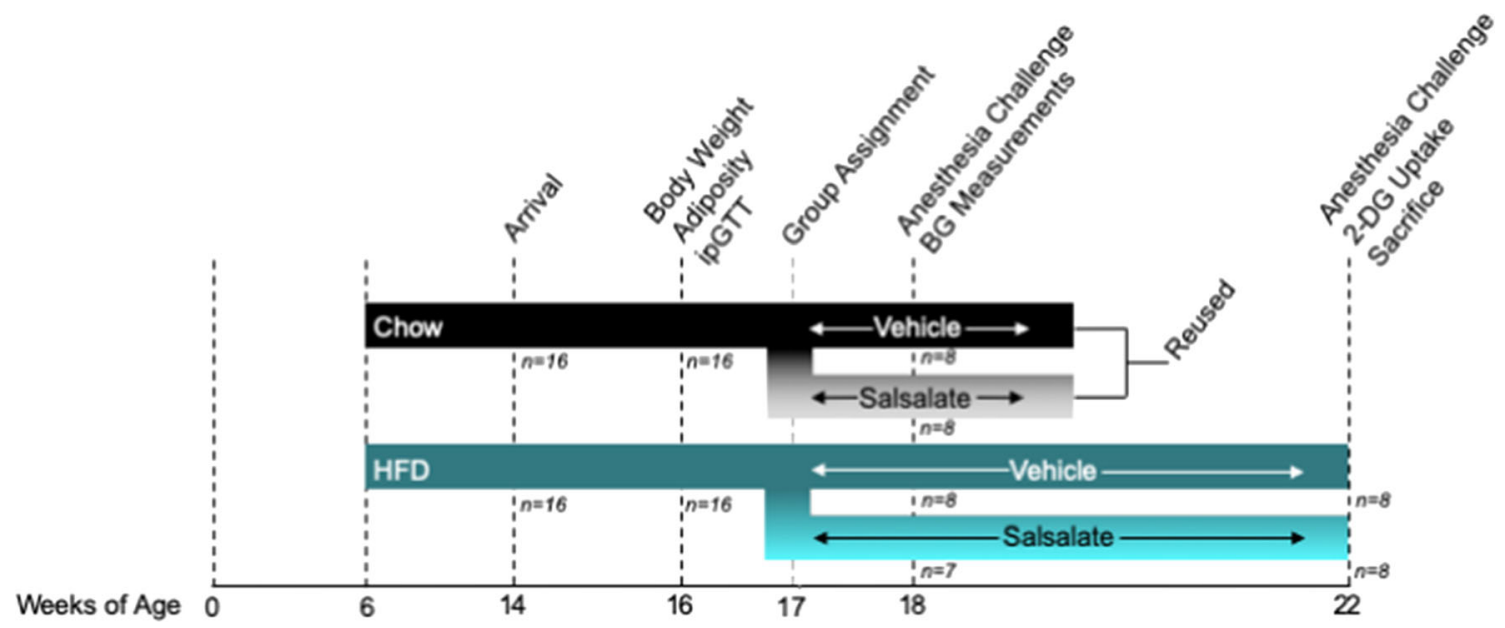

Figure 1 Timeline of experimental cohort. Fourteen-week-old male C57BL/6J mice fed a chow or $60 \%$ kcal from fat high-fat diet (HFD) were purchased (16/group) and allowed two weeks to acclimate. At 16 weeks of age, or ten weeks of HFD, body weight, adiposity, and glucose tolerance were measured for group assignment (Table). Mice on respective diets were ranked by intraperitoneal glucose tolerance test (ipGTT) area under the curve (AUC) before randomly being assigned to either vehicle or salsalate groups (8/group). Group means were then compared to determine any differences in these three factors. At 18 weeks of age, or 12 weeks of HFD, mice were pre- treated with vehicle or $62.5 \mathrm{mg} \cdot \mathrm{kg}^{-1}$ salsalate $30 \mathrm{~min}$ prior to sevoflurane anesthesia challenge. Subsequently, chow-fed mice were reused for pilot experiments. At 22 weeks of age, or 16 weeks of HFD, mice were exposed to the same pre-treatment and anesthesia challenge, with in vivo glucose uptake being measured starting at 60 min under sevoflurane anesthesia and continual maintenance of anesthesia until collection of tissues 
Blood measurements

Fasted blood glucose measurements were taken at 13:00 (6-hr) by nicking the tail vein. Serum insulin levels were measured using a commercially available ELISA (\#90080; Crystal Chem, Elk Grove Village, IL, USA) as per manufacturer's recommendations.

Glucose uptake in vivo

Glucose uptake in metabolic organs was assessed via tailvein infusion of $2 \mathrm{mCi}$ of ${ }^{3} \mathrm{H}$-2-deoxy-D-glucose (2-DG) five minutes after an intraperitoneal injection of $2.0 \mathrm{U} \cdot \mathrm{kg}^{-1}$ insulin. Blood glucose values were monitored every five minutes over the 20-min insulin stimulation timespan. Blood samples were taken at 10-, 15-, and 20-min timepoints relative to the insulin injection, deproteinized with $0.3 \mathrm{mM} \mathrm{ZnSO}_{4}$ and $0.3 \mathrm{mM} \mathrm{BaOH}$, and analyzed for 2 -DG radioactivity in a scintillation counter. Tissues were snap frozen and later processed for 2-DG radioactivity with and without deproteinization to determine tissue-specific rates of glucose uptake.

Sevoflurane anesthesia

Sevoflurane (SEVOrane \#04456; Abbvie, Saint-Laurent, QC, Canada) anesthesia (4\% for induction, and $2 \%$ for maintenance) was carried out using $100 \% \quad \mathrm{O}_{2}$ with a regulated cagemount Tec 3 quik-fill sevoflurane vaporizer (Benson Medical Industries Inc., Markham, ON, Canada). Briefly, mice were induced and anesthesia maintained in an induction box under a heat lamp throughout the entire experiment. Sevoflurane concentration was titrated to maintain a breathing frequency of 60-80 breaths $\cdot \min ^{-1}$, and mice were only removed briefly for blood sampling. Following anesthesia, mice were recovered on room air and observed for a period of one hour prior to returning to their native cages.

\section{Salsalate injection preparation}

To assess the acute effects of salsalate on blood glucose control under sevoflurane, salsalate (Cayman Chemicals) was dissolved in $100 \%$ dimethyl sulfoxide and suspended in 20\% 2-hydroxypropyl- $\beta$-cyclodextrin (Sigma-Aldrich, Oakville, ON, Canada) in saline to $5 \%$ DMSO as described. $^{23}$ The dose of $62.5 \mathrm{mg} \cdot \mathrm{kg}^{-1}$ salsalate was chosen based on previous findings in mice showing that it results in clinically relevant serum salicylate concentrations one hour after intraperitoneal injection. ${ }^{23}$ To this end, intraperitoneal injections of salsalate occurred 30 min prior to anesthetizing mice with sevoflurane so volatile exposure coincided with peak drug concentrations.
Statistics

A minimum sample size of six per group (chow-vehicle, chow-salsalate, DIO-vehicle, DIO-salsalate) was determined by power analysis of anticipated values (mu1 $=17$, mu $2=12$, sigma $=3$, power $=0.8$, alpha $=0.05)$. An extra two mice per group were ordered to account for any potential outliers discovered at the group-matching stage. All values were graphed on GraphPad Prism 9 as mean \pm standard error of the mean (SEM). No outliers were identified in this study as determined by the ROUT $(\mathrm{Q}=$ 1\%) method provided by GraphPad Prism 9 (San Diego, CA, USA). Data were analyzed using unpaired parametric Student's $t$ tests, repeated measures two-way analysis of variance (ANOVA) or two-way ANOVA with GeisserGreenhouse corrections and posthoc analysis using Sidak's multiple comparisons test with an alpha set to 0.05. Twoway ANOVA statistics are reported as $\mathrm{F}(\mathrm{DF})=\mathrm{F}$ statistic, $P$ value. Statistical differences were identified when $P<$ 0.05 .

\section{Results}

Sevoflurane induces hyperglycemia, and acute salsalate pre-treatment reduces the rise in blood glucose in both lean and obese mice exposed to sevoflurane

To explore the effects of sevoflurane on blood glucose control, male C57BL/6J mice were used as they are highly susceptible to DIO and the development of insulin resistance (Fig. 1). Diet-induced obese mice fed a $60 \%$ kcal from a high fat diet for ten weeks (hereafter referred to as obese mice) $(n=16)$ were significantly heavier, had higher adiposity, and were glucose intolerant compared with age-matched lean chow-fed mice challenged with a bolus of $0.8 \mathrm{~g} \cdot \mathrm{kg}^{-1}$ dextrose ( $n=16 /$ group) (Table). At 12 weeks of indicated diet, blood glucose was measured following a six-hour fast (basal) and following 30 and 60 min of anesthesia in both lean and obese mice. A two-way ANOVA revealed that sevoflurane anesthesia significantly increased blood glucose in both lean (Fig. 2A) $(\mathrm{F}(2)=69$; $P<0.001)$ and obese (Fig. 2B) $(\mathrm{F}(2)=26.96 ; P<0.001)$ mice; however, this anesthesia-induced hyperglycemia was attenuated at the 60 -min mark, as indicated by the change in blood glucose from basal to $60 \mathrm{~min}$, without statistical significance in lean ( $n=8$ /group) (Fig. 2A) (4.39 $\pm 0.55 \mathrm{vs}$ $2.79 \pm 0.71 \mathrm{mM} ; P=0.10)$ and a statistically significant difference in obese mice ( $n=7-8 /$ group) (Fig. 2B) (5.79 \pm 1.09 vs $1.91 \pm 1.32 \mathrm{mM} ; P=0.04)$ when salsalate $(62.5$ $\mathrm{mg} \cdot \mathrm{kg}^{-1}$ ) was administered $30 \mathrm{~min}$ before anesthesia. Importantly, salsalate pre-treatment in obese mice (11.79 \pm $1.78 \mathrm{mM}$ ) resulted in mean blood glucose values similar to 
TABLE Cohort parameters

\begin{tabular}{lrr}
\hline & \multicolumn{1}{c}{ C57BL/6J } & Diet-Induced Obesity \\
\cline { 2 - 3 } & Chow & $40.23 \pm 1.37 * * * *$ \\
\hline Body weight (g) & $27.13 \pm 0.25$ & $41.15 \pm 3.23 * * * *$ \\
Adiposity (\% body weight) & $12.80 \pm 0.95$ & $2192.00 \pm 153.64 * * * *$ \\
ipGTT AUC (mM*min) & $1428.63 \pm 30.31$ & $* 2.60$ \\
\hline
\end{tabular}

Values are mean \pm SEM from 16 mice per group. ipGTT AUC $=$ intraperitoneal glucose tolerance test area under the curve; SEM $=$ standard error of the mean

**** $P<0.001$ by Student's $t$ test
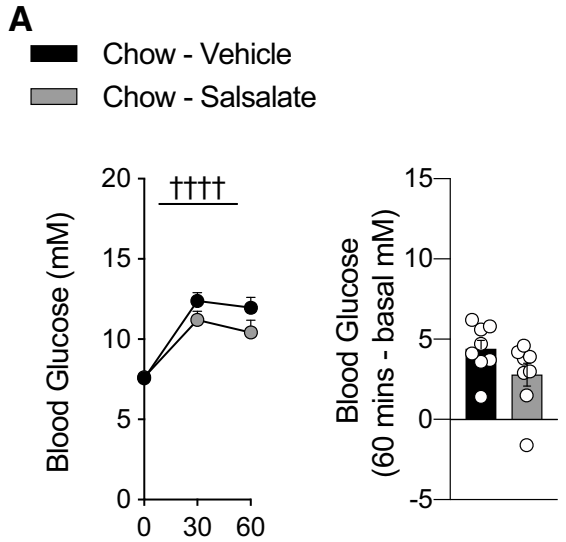

Time Under Anesthesia (mins)

Figure 2 Sevoflurane induces hyperglycemia, and acute salsalate pre-treatment reduces the rise in blood glucose in DIO mice exposed to sevoflurane. Blood glucose time plot and change in $(\Delta)$ blood glucose from basal to 60 min under anesthesia of mice anesthetized with sevoflurane on chow (A) and 60\% HFD (DIO) (B) for 12 weeks pre-treated with vehicle or salsalate 30 min prior. Data are means \pm SEM ( $n=7-8$ /group) $\dagger \dagger \dagger \dagger P<0.001$ denotes general anesthesia

vehicle-treated chow-fed mice $(11.96 \pm 0.65 \mathrm{mM})$ at 60-min under anesthesia (Fig. 2A and B).

Acute salsalate pre-treatment does not alter plasma insulin levels but increases glucose uptake into metabolic tissues of obese anesthetized mice

To examine potential mechanisms by which salsalate lowered blood glucose under anesthesia, we measured insulin levels and found by two-way ANOVA that sevoflurane increased plasma insulin in chow-fed mice $(\mathrm{F}(1)=19.17 ; P<0.001)$, but this was unaltered by salsalate $(\mathrm{F}(1)=0.1959 ; P=0.66 ; 95 \%$ confidence interval, -0.5434 to 0.3575 ) (Fig. 3A). In obese mice, basal insulin levels were higher than in chow-fed mice as expected $(\mathrm{F}(1)=50.05 ; P<0.001)$, but neither sevoflurane exposure nor salsalate pre-treatment altered plasma insulin levels (Fig. 3B). We also examined glucose uptake into different tissues using radiolabelled 2-deoxy-D-glucose. By
B
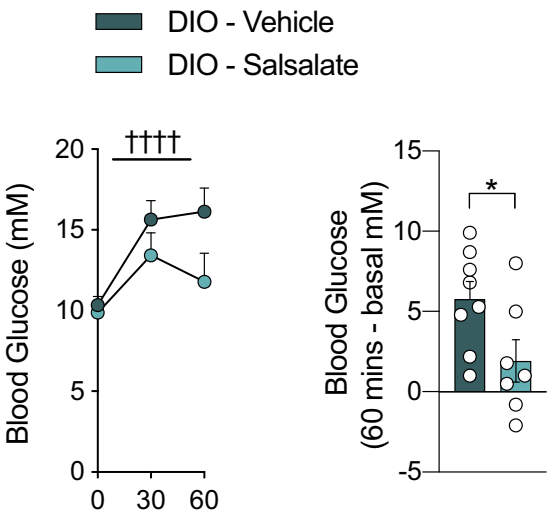

Time Under Anesthesia (mins)

effect as determined by repeated-measure two-way ANOVA, $* P<$ 0.05 salsalate $v s$ vehicle as indicated by Student's $t$ test. $\Delta=$ delta; ANOVA = analysis of variance; DIO = diet-induced obesity; HFD = high-fat diet; SEM = standard error of the mean

two-way ANOVA, we observed that salsalate pretreatment generally increased glucose uptake into brown adipose tissue (BAT), quadriceps (17.33 \pm 3.75 vs $23.17 \pm$ $5.72 \mu \mathrm{mol} \cdot \mathrm{g}^{-1}$ tissue $\left.\cdot \mathrm{hr}^{-1}\right)$, liver $(13.39 \pm 2.91$ vs $16.11 \pm$ $4.48 \mu \mathrm{mol} \cdot \mathrm{g}^{-1}$ tissue $\cdot \mathrm{hr}^{-1}$ ), inguinal white adipose tissue $\left(7.16 \pm 1.85\right.$ vs $10.52 \pm 2.69 \mu \mathrm{mol} \cdot \mathrm{g}^{-1}$ tissue $\left.\cdot \mathrm{hr}^{-1}\right)$, and gonadal white adipose tissue $(9.35 \pm 1.41$ vs $11.46 \pm 1.38$ $\mu \mathrm{mol} \cdot \mathrm{g}^{-1}$ tissue $\left.\cdot \mathrm{hr}^{-1}\right)$ (Fig. 4) $(\mathrm{F}(1)=7.995 ; P=0.006)$. Interestingly, there was a $\sim 1$.7-fold increase in glucose uptake into BAT (Fig. 4) (45.28 \pm 4.57 vs $76.89 \pm 12.23$ $\mu \mathrm{mol} \cdot \mathrm{g}^{-1}$ tissue $\left.\cdot \mathrm{hr}^{-1} ; P<0.001\right)$. These data suggest that salsalate increases glucose uptake into peripheral tissues, particularly BAT, independently of changes in plasma insulin during anesthesia. 
A

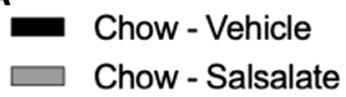

B
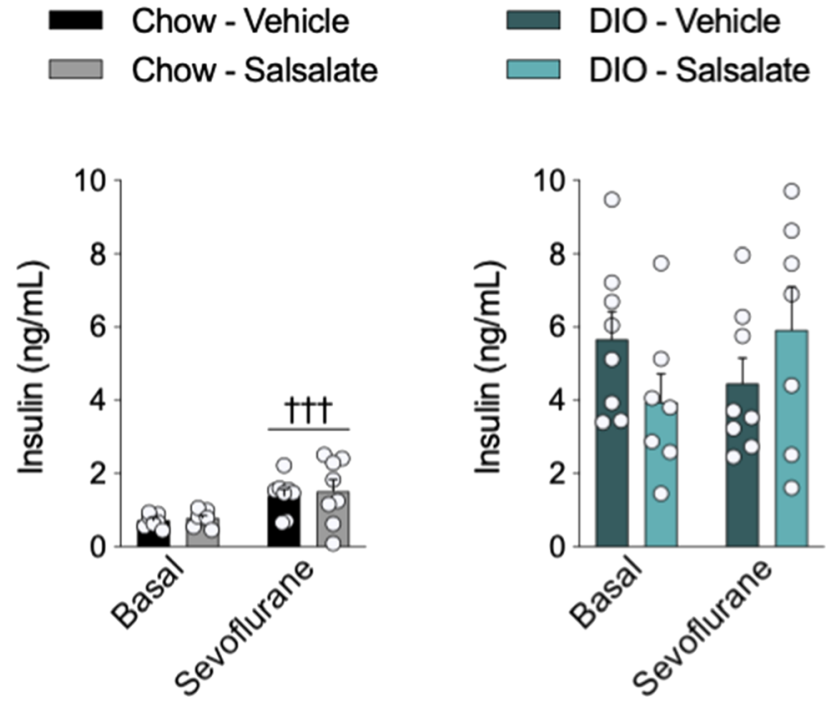

Figure 3 Sevoflurane increases circulating insulin in lean but not DIO mice, and is unaffected by salsalate pre-treatment. Serum insulin concentrations in blood collected from six-hour fasted mice pretreated with vehicle or salsalate prior to (basal) and $60 \mathrm{~min}$ following sevoflurane anesthesia (sevoflurane) on chow (A) or 60\% HFD (DIO) (B). Data are means \pm SEM ( $n=7$-8/group). $\dagger \dagger \uparrow P<0.001$ denotes a general anesthesia effect as indicated by repeated-measure two-way ANOVA. ANOVA = analysis of variance; DIO = diet-induced obesity; SEM = standard error of the mean

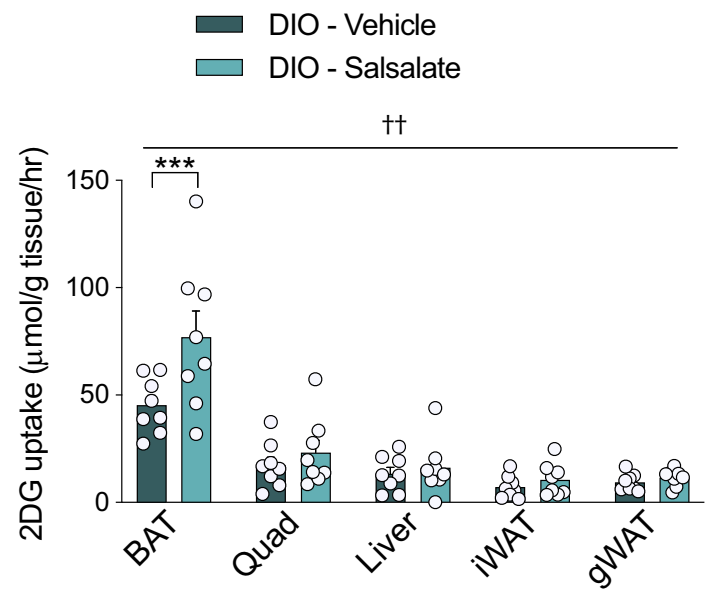

Figure 4 Salsalate pre-treatment increases insulin-stimulated glucose uptake into tissues of DIO mice under sevoflurane anesthesia. H-2-deoxy-D-glucose (2-DG) uptake into brown adipose tissue (BAT), quadriceps (Quad), liver, inguinal white adipose tissue (iWAT), and gonadal white adipose tissue (gWAT) of mice pretreated with respective vehicle or salsalate, fasted for six hours and stimulated with $2 \mathrm{U} \cdot \mathrm{kg}^{-1}$ insulin. Data are means $\pm \mathrm{SEM}(n=$ $7-8 /$ group). $\dagger \dagger P<0.01$ denotes a general salsalate effect as indicated by repeated-measure two-way ANOVA, $* * * P<0.001$ salsalate $v s$ vehicle as indicated by Sidak's multiple comparisons test. ANOVA = analysis of variance; DIO = diet-induced obesity; SEM = standard error of the mean

\section{Discussion}

Anesthetics, including volatiles, are known to cause hyperglycemia in adult rodents and humans. ${ }^{12,13,16}$ Consistent with previous findings, sevoflurane induced hyperglycemia in both lean insulin-sensitive and DIO insulin-resistant mice. Clinically, glucose intolerance has been reported after prolonged ( $\sim$ ten hours) anesthesia in "healthy" patients; however, these patients were also undergoing extensive head and neck reconstructive surgeries that may also have had an effect. ${ }^{26}$ The measured increases in blood glucose we observed raise several important questions, including whether metabolically compromised patients with pre-existing dysglycemia have more pronounced hyperglycemic events when anesthetized. In turn, this may lead to several detrimental effects including impaired recovery and healing. ${ }^{7,27}$

Acute pre-treatment with salsalate resulted in a meaningful $4.3 \mathrm{mM}$ reduction in peak blood glucose in obese mice anesthetized with sevoflurane, without causing any hypoglycemic events. Furthermore, it is important to note that these effects were only seen with an acute pretreatment and not in mice chronically fed a diet supplemented with salsalate (eFigure, ESM). A possible explanation for this difference is that chronic salsalate was provided orally through diet, and when mice were fasted for six hours they may not have maintained clinically relevant concentrations of the drug whose half-life is reported to range from one to four hours. ${ }^{23,28}$ In contrast, injecting salsalate $30 \mathrm{~min}$ before anesthesia allowed the drug to reach peak concentrations around $30 \mathrm{~min}$ into sevoflurane exposure when glucose levels started to increase. It seems likely that such reductions seen in blood glucose may offer clinical benefit. Previously, Umpierrez et al. showed significant improvements in composite outcomes including wound infection, pneumonia, bacteremia, respiratory failure, and acute renal failure with a reduction of approximately $1 \mathrm{mM}$ blood glucose. $^{7}$ This was accomplished through a basalbolus insulin $v s$ a standard insulin sliding scale regimen. Nevertheless, using insulin perioperatively was also associated with severe hypoglycemia in $3.8 \%$ of patients, which is associated with detrimental outcomes. ${ }^{7}$ Similarly, others found that the continuation of metformin and/or sulfonylureas also significantly lowered perioperative blood glucose levels by $1 \mathrm{mmol} \cdot \mathrm{L}^{-1}$ in ambulatory patients without causing any hypoglycemic events. ${ }^{29}$ Together, this supports the notion that the use of oral glucose-lowering medications may offer a viable alternative to improve perioperative glycemic control. ${ }^{8,9,29}$ Our rodent data suggest that salsalate may offer a viable and powerful alternative to improve 
perioperative glucose control in addition to antiinflammatory and analgesic properties, ${ }^{30}$ and warrants further clinical investigation.

Salsalate has been reported to lower blood glucose by reducing insulin clearance. $^{31-33}$ In contrast to these findings, we found that insulin levels were unaltered by salsalate, likely because of the acute nature of our treatment paradigm compared with the chronic treatments assessed previously. ${ }^{32}$ Instead, we found that reductions in blood glucose were associated with enhanced glucose uptake, specifically into BAT. Salicylate, which is the active component of salsalate, has been shown to induce mitochondrial uncoupling in primary hepatocytes, an effect which supports the evidence that salsalate can increase fat oxidation in the basal state and higher oxidative glucose disposal in an insulin-stimulated state. ${ }^{23,33}$

While BAT has long been known to be present in rodents and babies, it was thought to have a minimal role in controlling blood glucose in adults. Nevertheless, recent studies have highlighted that the activation of BAT in adults is associated with improvements in glucose homeostasis. $^{34-38}$ Importantly, consistent with our findings with salsalate, these increases in glucose disposal in BAT can occur independently of increases in insulin. Future studies investigating whether salsalate enhances BAT glucose disposal in humans are warranted.

In conclusion, we have shown that sevoflurane promotes hyperglycemia in both lean and obese mice, and that these effects are partially attenuated with salsalate pre-treatment. These data suggest that salsalate may represent a novel means to safely lower perioperative blood glucose without causing hypoglycemia. Whether this can be translated to the clinical realm remains the subject of further investigation.

\begin{abstract}
Author contributions Eric M. Desjardins, Gregory R. Steinberg, and Russell E. Brown designed the experiments. Eric M. Desjardins and Russell E. Brown performed the experiments. Eric M. Desjardins analyzed the data. B.K.S. provided technical expertise and intellectual contributions. Eric M. Desjardins, Gregory R. Steinberg, and Russell E. Brown wrote the manuscript. All authors edited the manuscript and provided comments.
\end{abstract}

Acknowledgements The authors would like to thank Julian Yabut, Eric Chan, Marisa Morrow and Jianhan Wu for their assistance in performing the 2-DG experiment.

\section{Disclosures None.}

Funding statement This study was supported by grants from the Hamilton Health Sciences Anesthesia Research Fund (R.E.B. 3576.301819), the Canadian Institutes of Health Research (G.R.S. 201709FDN-CEBA-116200), and Diabetes Canada (G.R.S. DI-5-175302-GS). E.M.D. is a Vanier Scholar. G.R.S. is supported by a Canada Research Chair and a J. Bruce Duncan Chair in Metabolic Diseases.
Editorial responsibility This submission was handled by Dr. Gregory L. Bryson, former Deputy Editor-in-Chief, Canadian Journal of Anesthesia.

\section{References}

1. Kotagal $M$, Symons $R G$, Hirsch $I B$, et al. Perioperative hyperglycemia and risk of adverse events among patients with and without diabetes. Ann Surg 2015; 261: 97-103.

2. Marchant MH Jr, Viens NA, Cook C, Vail TP, Bolognesi MP. The impact of glycemic control and diabetes mellitus on perioperative outcomes after total joint arthroplasty. J Bone Joint Surg Am 2009; 91: 1621-9.

3. Frisch A, Chandra P, Smiley D, et al. Prevalence and clinical outcome of hyperglycemia in the perioperative period in noncardiac surgery. Diabetes Care 2010; 33: 1783-8.

4. Palermo NE, Gianchandani RY, McDonnell ME, Alexanian SM. Stress Hyperglycemia during surgery and anesthesia: pathogenesis and clinical implications. Curr Diabetes Rep 2016; DOI: https://doi.org/10.1007/s11892-016-0721-y.

5. Zhang X, Yan X, Gorman J, Hoffman SN, Zhang L, Boscarino JA. Perioperative hyperglycemia is associated with postoperative neurocognitive disorders after cardiac surgery. Neuropsychiatr Dis Treat 2014; 10: 361-70.

6. Huang $P$, Lin $M$, Wen $J$, et al. Correlation of early postoperative blood glucose levels with postoperative complications, hospital costs, and length of hospital stay in patients with gastrointestinal malignancies. Endocrine 2015; 48: 187-94.

7. Umpierrez GE, Smiley D, Jacobs $S$, et al. Randomized study of basal-bolus insulin therapy in the inpatient management of patients with type 2 diabetes undergoing general surgery (RABBIT 2 surgery). Diabetes Care 2011; 34: 256-61.

8. Duggan EW, Carlson K, Umpierrez GE. Perioperative hyperglycemia management: an update. Anesthesiology 2017; 126: 547-60

9. Brown R, Siddiqui U, Paul J. A survey: perioperative diabetes medications and glucose control-time to re-examine management? Can J Anesth 2019; 66: 621-2.

10. Otto JG. Ueber den gehalt des blutes an zucker und reducierender substanz unter verschiedenen umstanden (German). Pflügers Arch 1885; 35: 467-98.

11. Maloney AH, Graves B Jr, Rhodes LC. Metabolic changes in anesthesia under various states of nutrition. J Natl Med Assoc 1949; 41: 202-14.

12. Sato K, Kitamura T, Kawamura $G$, et al. Glucose use in fasted rats under sevoflurane anesthesia and propofol anesthesia. Anesth Analg 2013; 117: 627-33.

13. Diltoer M, Сати F. Glucose homeostasis and insulin secretion during isoflurane anesthesia in humans. Anesthesiology 1988; 68: 880-6.

14. Saho S, Kadota Y, Sameshima T, Miyao J, Tsurumaru T, Yoshimura $N$. The effects of sevoflurane anesthesia on insulin secretion and glucose metabolism in pigs. Anesth Analg 1997; 84: 1359-65.

15. Kim SP, Broussard JL, Kolka CM. Isoflurane and sevoflurane induce severe hepatic insulin resistance in a canine model. PLoS One 2016; DOI: https://doi.org/10.1371/journal.pone.0163275.

16. Yu $Q, L i J$, Dai $C L$, et al. Anesthesia with sevoflurane or isoflurane induces severe hypoglycemia in neonatal mice. PLoS One 2020; DOI: https://doi.org/10.1371/journal.pone.0231090. 
17. NICE-SUGAR Study Investigators, Finfer S, Chittock DR, et al. Intensive versus conventional glucose control in critically ill patients. N Engl J Med 2009; 360: 1283-97.

18. Goldfine AB, Fonseca V, Jablonski KA, Pyle L, Staten MA, Shoelson SE. The effects of salsalate on glycemic control in patients with type 2 diabetes: a randomized trial. Ann Intern Med 2010; 152: 346-57.

19. Goldfine AB, Silver R, Aldhahi $W$, et al. Use of salsalate to target inflammation in the treatment of insulin resistance and type 2 diabetes. Clin Transl Sci 2008; 1: 36-43.

20. Goldfine $A B$, Conlin $P R$, Halperin $F$, et al. A randomised trial of salsalate for insulin resistance and cardiovascular risk factors in persons with abnormal glucose tolerance. Diabetologia 2013; 56: 714-23.

21. Salastekar N, Desai T, Hauser $T$, et al. Salsalate improves glycaemia in overweight persons with diabetes risk factors of stable statin-treated cardiovascular disease: a 30-month randomized placebo-controlled trial. Diabetes Obes Metab 2017; 19: 1458-62.

22. Steinberg GR, Dandapani $M$, Hardie DG. AMPK: mediating the metabolic effects of salicylate-based drugs? Trends Endocrinol Metab 2013; 24: 481-7.

23. Smith BK, Ford RJ, Desjardins EM, et al. Salsalate (salicylate) uncouples mitochondria, improves glucose homeostasis, and reduces liver lipids independent of AMPK-B1. Diabetes 2016; 65: 3352-61.

24. Ford RJ, Fullerton MD, Pinkosky SL, et al. Metformin and salicylate synergistically activate liver AMPK, inhibit lipogenesis and improve insulin sensitivity. Biochem J 2015; 468: 125-32.

25. King AJ. The use of animal models in diabetes research. $\mathrm{Br} \mathrm{J}$ Pharmacol 2012; 166: 877-94.

26. Iwasaka $H$, Itoh $K$, Miyakawa $H$, Kitano $T$, Taniguchi $K$, Honda $N$. Glucose intolerance during prolonged sevoflurane anaesthesia. Can J Anaesth 1996; 43: 1059-61.

27. de Vries FE, Gans SL, Solomkin JS, et al. Meta-analysis of lower perioperative blood glucose target levels for reduction of surgical-site infection. Br J Surg 2017; 104: e95-105.

28. Harrison LI, Funk ML, Re ON, Ober RE. Absorption, biotransformation, and pharmacokinetics of salicylsalicylic acid in humans. J Clin Pharmacol 1981; 21: 401-4.

29. Gasanova I, Meng J, Minhajuddin A, Melikman E, Alexander JC, Joshi GP. Preoperative continuation versus interruption of oral hypoglycemics in type 2 diabetic patients undergoing ambulatory surgery: a randomized controlled trial. Anesth Analg 2018; 127: e54-6.

30. Cheng $G$, Cassissi C, Drexler PG, Vogel SB, Sninsky CA, Hocking MP. Salsalate, morphine, and postoperative ileus. Am J Surg 1996; 171: 85-8.

31. Anderson $K$, Wherle L, Park M, Nelson K, Nguyen L. Salsalate, an old, inexpensive drug with potential new indications: a review of the evidence from 3 recent studies. Am Health Drug Benefits 2014; 7: 231-5.

32. Koska J, Ortega E, Bunt JC, et al. The effect of salsalate on insulin action and glucose tolerance in obese non-diabetic patients: results of a randomised double-blind placebocontrolled study. Diabetologia 2009; 52: 385-93.

33. Meex RC, Phielix E, Moonen-Kornips E, Schrauwen P, Hesselink $M K$. Stimulation of human whole-body energy expenditure by salsalate is fueled by higher lipid oxidation under fasting conditions and by higher oxidative glucose disposal under insulin-stimulated conditions. J Clin Endocrinol Metab 2011; 96: 1415-23.

34. Hanssen MJ, Hoeks J, Brans B, et al. Short-term cold acclimation improves insulin sensitivity in patients with type 2 diabetes mellitus. Nat Med 2015; 21: 863-5.

35. Hanssen MJ, van der Lans AA, Brans B, et al. Short-term cold acclimation recruits brown adipose tissue in obese humans. Diabetes 2016; 65: 1179-89.

36. Flier JS. Might B3-adrenergic receptor agonists be useful in disorders of glucose homeostasis? J Clin Invest 2020; 130: 2180-2.

37. Finlin BS, Memetimin $H, Z h u B$, et al. The B3-adrenergic receptor agonist mirabegron improves glucose homeostasis in obese humans. J Clin Invest 2020; 130: 2319-31.

38. O'Mara AE, Johnson JW, Linderman JD, et al. Chronic mirabegron treatment increases human brown fat, HDL cholesterol, and insulin sensitivity. J Clin Invest 2020; 130: 2209-19.

Publisher's Note Springer Nature remains neutral with regard to jurisdictional claims in published maps and institutional affiliations. 